Old Dominion University

ODU Digital Commons

\title{
Viability of Using Twitter to Support Peer Instruction in Teacher Education
}

Tian Luo

Old Dominion University

Danielle E. Dani

Li Cheng

Follow this and additional works at: https://digitalcommons.odu.edu/stemps_fac_pubs

Part of the Curriculum and Instruction Commons, and the Social Media Commons

\section{Original Publication Citation}

Luo, T., Dani, D. E., \& Cheng, L. (2016). Viability of using Twitter to support peer instruction in teacher education. International Journal of Social Media and Interactive Learning Environments, 4(4), 287-304. doi: http://dx.doi.org/10.1504/IJSMILE.2016.081280

This Article is brought to you for free and open access by the STEM Education \& Professional Studies at ODU Digital Commons. It has been accepted for inclusion in STEMPS Faculty Publications by an authorized administrator of ODU Digital Commons. For more information, please contact digitalcommons@odu.edu. 


\title{
Viability of using Twitter to support peer instruction in teacher education
}

\author{
Tian Luo* \\ Instructional Design and Technology, \\ Department of STEM Education and Professional Studies, \\ Darden College of Education, \\ Old Dominion University, \\ Norfolk, VA 23529, USA \\ Email: tluo@odu.edu \\ *Corresponding author
}

\section{Danielle E. Dani}

Science Education,

Department of Teacher Education,

Gladys W. and David H. Patton College of Education,

Ohio University,

Athens, OH 45701, USA

Email: dani@ohio.edu

\section{Li Cheng}

Educational Technology,

School of Teaching and Learning,

College of Education,

University of Florida,

Gainesville, FL 32611, USA

Email: licheng@ufl.edu

\begin{abstract}
This paper reports on a case study in which Twitter served as a backchannel to mediate and support the peer-teaching activity in a face-to-face teacher education course. Surveys and interviews were utilised to understand the effectiveness of the Twitter integration and students' perceived learning in a Twitter-supported peer teaching environment. Tweets were used to determine how preservice teachers used Twitter to support peer instruction. Most students were able to use the Twitter platform to produce and retrieve peer feedback, while some encountered technical difficulties. Our current analysis suggests the Twitter-based peer feedback was moderately successful in this peer teaching activity. There exists a large variability of students' perceptions towards Twitter as a tool to support the delivery and reception of peer feedback.
\end{abstract}

Keywords: microblogging; Twitter; feedback; peer instruction; Web 2.0; social media. 
Reference to this paper should be made as follows: Luo, T., Dani, D.E. and Cheng, L. (2016) 'Viability of using Twitter to support peer instruction in teacher education', Int. J. Social Media and Interactive Learning Environments, Vol. 4, No. 4, pp.287-304.

Biographical notes: Tian Luo is an Assistant Professor in the Instructional Design and Technology program at Old Dominion University. Formerly, she had worked as an instructional design professional in both higher education and corporate settings. She currently serves as a Co-Editor of Journal of Information Technology Education (Research \& Innovations in Practice) and has been a reviewer for many peer-reviewed journals and conferences. Her research interests' centre on using social media to facilitate student learning and designing collaborative and authentic learning environments supported and enhanced by emerging web-based technologies.

Danielle E. Dani holds a BS and MS in Biology from the American University of Beirut, in Beirut, Lebanon. In 2004, she received her PhD in Education from the University of Cincinnati. She is an Associate Professor in the Department of Teacher Education, where she teaches undergraduate and graduate courses in secondary, middle childhood, and early childhood education, as well as courses in curriculum and instruction. Her research investigates strategies for developing teacher knowledge and skills for teaching STEM ideas and practices in place-based and culturally relevant ways. She is additionally interested in promoting teacher development through a focus on reflection, discourse, and action research.

Li Cheng is a Doctoral student in the Educational Technology program at University of Florida where she works as a Graduate Instructor and a Research Assistant. She has been serving as an assistant to the editor of the Excellence in Education Journal and a reviewer for peer-reviewed journals. Her research interests focus on facilitating student learning through effective technology integration in formal and informal educational settings and designing technology-enhanced learning environments.

This paper is a revised and expanded version of a paper entitled 'Using Twitter to support peer instruction: a case study' presented at 2015 International Conference of Educational Innovation through Technology (EITT), Wuhan, China, 16-18 October 2015.

\section{Introduction}

Peer instruction is a unique instructional strategy that involves one or more students teaching other students a particular subject area (Whitman, 1988). A plethora of research has evidenced that peer instruction is an effective means to engage students in active learning, holding students accountable in reviewing and evaluating each other's work, and creating a dynamic and active collaborative learning environment through the exchange of peer feedback (Crouch and Mazur, 2001; Fagen et al., 2002; Farivar and Webb, 1993; Rourke and Anderson, 2010). Feedback, according to multiple instructional design theories, is an indispensable aspect of designing effective instruction, leading to continuous and dynamic social interactions towards improved learning outcomes (Gagné et al., 1992; Gropper, 1983; Merrill, 1983). The purpose of this exploratory case 
study is to examine how the use of Twitter, as a microblogging tool, supports feedback and peer instruction in a traditional teacher education class.

\section{Literature review}

\subsection{Peer instruction in teacher education}

Peer instruction is the most widely used strategy for providing preservice teachers with clinical experiences on the university campus. Traditionally, peer instruction is used to promote preservice teachers' development of particular teaching skills using a microteaching lesson and feedback (Metcalf, 1993; Mills, 1991). In this section, we elaborate on the microteaching lesson component of peer instruction and address the feedback component in the next section.

A microteaching lesson enables preservice teachers to develop a deeper conceptual understanding of the content and skills conducive to developing complex reasoning skills (Crouch and Mazur, 2001; Whitman, 1988). Using peer instruction, preservice teachers learn more effectively, becoming actively engaged with the material learned, receive an opportunity to practice teaching skills first hand, while also helping them closely connect with the content (Rosenberg et al., 2006). Prior research showed that peer instruction has enhanced student learning both on cognitive (CG) and AF levels, helping students reprocess and replicate the content materials in preparation for peer teaching. This elevates their motivation and intrinsic drive to learn in the peer-to-peer learning process (Whitman, 1988).

Successful peer instruction teaching practices can take various forms. The key elements of successful peer instruction consist of multiple episodes of interactive class activities that require students to apply what they learn, then display the ability to present or explain the learned content to fellow students. Discussion groups, seminars, tutoring sessions, or teaching presentations led by students are historically-known common methods of peer instruction (Goldschmid and Goldschmid, 1976). More recent research also exalts a more systematic and all-encompassing integration of peer instruction, favouring such integration to be placed in multiple stages within one class period (Crouch et al., 2007; Rosenberg et al., 2006). Rosenberg et al. (2006) noted that peer instruction can be integrated across a variety of interactive engagement practices, including: pre-class reading activities, between-class mini-lectures, formative, short, and conceptual questions interspersed with mini-lectures, as well as discussions. A key characteristic of the microteaching lesson in teacher education is that the lesson is video-recorded. The preservice teacher, alone or together with others, views the recording, analyses instruction, and reflects on the process. Peer and instructor feedback often informs the analysis and the reflection process.

\subsection{Feedback in peer instruction}

Feedback is a tool often used to provide comments, advice, and suggestions to improve the work of another. Feedback can occur in various forms including informal conversations in face-to-face settings, formal or informal writing through e-mail or discussion forum posts, and typed or hand-written documents similar to reports. In peer instruction, feedback is given from an instructor to students and from peers to peer 
teacher(s). Instructor feedback serves as an effective tool for scaffolding peer feedback whereby the instructor models the ideal act of critiquing, offering explanations and suggestions, inviting more views and opinions, or providing emotional support (Puntambekar and Hubscher, 2005). At minimum, the purpose of providing feedback is twofold. On the CG level, providing useful feedback can help improve performance by filling the gap between actual performance and desired performance (Whitman, 1988). Instructor-provided feedback is often more effective in ameliorating the gap because instructors possess a greater understanding of the course materials, thus granting greater accuracy with assessment. However, Metcalf (1993, p.172) found that groups "who are provided guidance may be as effective in promoting desirable outcomes in laboratory settings as feedback provided by the instructor". On the AF level, the simple act of helping one another by providing emotional feedback and support re-emphasises a social learning environment where all learners can support each other. This exemplifies the ethos of social, constructive learning (Vygotsky, 1978).

Over the years, scholars have proposed various frameworks to conceptualise feedback. The distinction between CG and AF feedback as discussed above echoes what Nelson and Schunn (2009) proposed in their system of feedback classification. Other scholars conceptualise the construct of feedback in terms of its purpose, relevance, specificity, timing, and frequency (Nottingham and Henning, 2014). Constructive feedback has increasingly garnered attention from both researchers and practitioners, as it clamors for a highly rigorous form of evaluative feedback. It identifies problems and issues based on objective, norm- or criteria- references, albeit presenting the problems and suggesting solutions in a well-reasoned, friendly, and non-offensive fashion (Du Toit, 2012; Duffy, 2013; Hendry et al., 2011). Research indicates how constructive feedback can take place in three forms:

a criticisms

b questions

c suggestions for improvements (Brookhart, 2008).

These frameworks shed light on the interpretation and evaluation of feedback.

\subsection{Using Web 2.0 technology in peer instruction}

Web 2.0 technologies are commonly used under the context of peer instruction. Affordances of these Web 2.0 tools have supported pedagogical innovation offering learners and teachers more freedom and flexibility when engaged in peer instruction activities (McLoughlin and Lee, 2007). For example, blogs have been an exemplary tool encouraging reflective practices on the content material, as well as gaining information literacy skills (Chan and Cmor, 2009; Hall and Davison, 2007). Many Web 2.0 tools can be intentionally and strategically designed for adoption within traditional classrooms or any other learning environments, thus providing support and scaffolding for complex student learning (Puntambekar and Hubscher, 2005).

Recently, as another exemplar of Web 2.0 technologies, microblogging tools such as Twitter have been widely appropriated by educators into educational settings to enhance the interactivity of classroom learning (Gao et al., 2012; Holotescu and Grosseck, 2009). Research has shown that Twitter could promote classroom conversations by providing an online backchannel for participation (Costa et al., 2008; Dunlap and Lowenthal, 2009; 
Luo and Gao, 2012). The availability of a virtual microblogging platform allows for students' instant and immediate participation, which can be an ideal environment for peer feedback. Microblogging makes an adept venue for delivering peer (or instructor) feedback as it eases and accelerates the feedback process by making all feedback easily accessible and readily available in the online environment without the instructor administering it. Students can post their feedback tweets immediately when they have questions and comments without directing their comments to the instructor. They may also search for peer feedback using the search function in a microblogging system in lieu of awaiting peer feedback collected by the instructor. However, research regarding the use of microblogging and results of curriculum or instructional design involving microblogging integration remain limited (Warren, 2016).

In our study, we adopted Twitter to mediate the delivery of peer feedback throughout the time of students' peer teaching activities. This study aims to explore the usefulness of using microblogging to support peer teaching in a teacher education classroom and examine the process of providing peer feedback mediated by Twitter as compared to paper-based peer instruction. We purport to understand the role that Twitter played in the peer teaching activity, and whether it supported peer instruction, and the ways it provided support (or hampered) peer instruction.

\subsection{Research questions}

The purpose of this exploratory case study is to examine how the use of Twitter, as a microblogging tool, supports peer instruction in a traditional teacher education class. As mentioned previously, research regarding the use of microblogging and results of curriculum or instructional design involving microblogging integration remain limited (Warren, 2016). The following research questions were used to guide this study:

1 What were students' perceptions towards Twitter as a tool to support the delivery and reception of peer feedback?

2 What were the instructor's perceptions towards Twitter as a tool to support the delivery and reception of peer feedback?

3 How was the quality of Twitter-supported peer feedback as compared to paper-based feedback?

4 What are the pedagogical implications and practical suggestions for future Twitter integration in the context of peer instruction?

\section{Methods}

This study used a case study design (Yin, 2008) that aimed to investigate the research questions in great depth. Participants were 30 preservice teachers, ages ranging from 19 to 24 , enrolled in the early childhood and middle childhood teacher education program at a Midwestern, rural university. The study investigates the integration of Twitter to allow the researchers to explore the instructional use of Twitter, as well as its potential contributions to student learning. Twitter was specifically selected for use in this course 
because of its research supported potential to enhance the timeliness of feedback, students' interest, motivation, and engagement (Borau et al., 2009; Costa et al., 2008).

\subsection{Instructional context}

The study took place in two science methods courses at a Midwestern, rural university. The early childhood science methods course is required in the junior year of the program, while the middle childhood science methods course is required in the junior or senior year. In both courses, the curriculum focuses on topics that are central to science education including, among others, scientific practices (inquiry), engineering practices, safety, science teaching strategies, and assessments in science. The science methods curriculum also emphasises skills and dispositions that are key to the development of preservice teachers' professional knowledge including reflection, professional development, and growth among others. The peer-teaching project constituted one of the requirements of each of the science methods courses. For this project, preservice teachers were expected to design a science lesson plan using one of the strategies for teaching science, teach their lesson to their peers (40 minutes), and then reflect on their general and strategy specific science teaching skills (due one week after the peer teaching session). Peer teaching occurred during multiple class sessions spanning eight weeks in each course.

\subsection{Research implementation and data collection}

The implementation of the Twitter integration followed a design-based approach in which the activities to be included into the class curriculum were designed, implemented, and assessed by the researchers. The activities and methods of Twitter usage were written into the class syllabus as part of the curriculum, aiming to ensure the legitimacy and the actual implementation of the Twitter-involved activities.

Prior to the start of the peer teaching project, the first author provided brief training of Twitter incorporation within the course. Then, the course instructor (second author) modelled a lesson that used the target teaching strategy. The researchers then introduced a typology of feedback, ranging from simple praise to constructive remarks. While peer teacher(s) were facilitating their lesson during class time, peers who were engaged in the lesson as students used paper and pencil or Twitter to provide feedback. Preservice teachers were required to provide at least 'two stars and two wishes' to the peer teachers. This is representative of what they perceived as strengths and areas for improvement.

Each peer teaching session lasted approximately 40 minutes. To scaffold the peer instruction process, the researchers provided preservice teachers with a recording of their peer teaching session and feedback from their peers. Preservice teachers were instructed to use the recording of their lesson and feedback from their peers to analyse and reflect on their practice. The students used paper and pencil to provide handwritten feedback to peer teachers during the first half of the project, followed by Twitter-based feedback in the second half of the project.

The paper and Twitter feedback was used to examine the types of feedback that preservice teachers provided, and whether or not the contents of the feedback differed between the two mediums. The instructor also provided preservice peer teachers with two types of feedback: Twitter-based feedback immediately after the end of the peer teaching session and paper-based feedback a week later. The instructor feedback was also 
analysed to determine the type of feedback provided by the instructor. By the end of the course, students were asked to voluntarily fill out a survey with open-ended questions to report their experience of this peer teaching activity, as well as provide their perceptions of the Twitter integration. An interview with the instructor was also conducted as a space to provide her reflection.

\subsection{Data analysis}

\subsubsection{Twitter and paper feedback}

The student Twitter- and paper-based feedback was analysed from both quantitative and qualitative dimensions to provide insight on the nature of student interactions and Twitter-mediated peer-feedback, as compared to paper-feedback. The quantitative dimension included

a the number of students who participated

b the average number of messages each student posted

c the average character of posting

d average word length per post.

Qualitative content analysis was also used to analyse student tweets using a typology of feedback that was developed using the conceptual frameworks described in the literature (Duffy, 2013; Du Toit, 2012; Brookhart, 2008; Nelson and Schunn, 2009). First, we analysed all feedback and assigned it to one of two broad categories: CG or AF feedback. Any comments that were irrelevant to the peer instruction exercise were coded as not relevant (NR). We labelled this initial step in coding classification 1. Next, we analysed the feedback within the CG category to identify constructive feedback; we named this step classification 2. In general, we considered constructive feedback as constructive criticism that can pinpoint problems, raise questions, and provide suggestions. We then coded all the constructive feedback into three measures, Suggestion (SG), Criticism (CT), and Question (QT) accordingly. Table 1 presents sample tweets collected in our data. The level of agreement for classification 1 between two coders was $91.1 \%$ and $100 \%$ for Twitter and paper posts, respectively. For classification 2, the level of coder agreement was $88.3 \%$ for Twitter and $94.3 \%$ for paper feedback. Disagreements were later resolved through discussion.

\subsubsection{Student and instructor perceptions}

An end of course survey was used to examine students' perceptions about their experience in the Twitter-mediated peer feedback sessions. The survey consisted of four sets of Likert-scale items on the effectiveness of Twitter integration on varying dimensions. Open-ended questions were also included asking students to justify their ratings by providing additional comments about their interactions and classroom experience using Twitter. Finally, an informal interview was used to elicit the course instructor's perceptions regarding the use of Twitter-based feedback in the peer teaching exercise. The interview focused on the instructor's use of Twitter and her perceptions of students' use of Twitter-based feedback. 
Table 1 Sample feedback

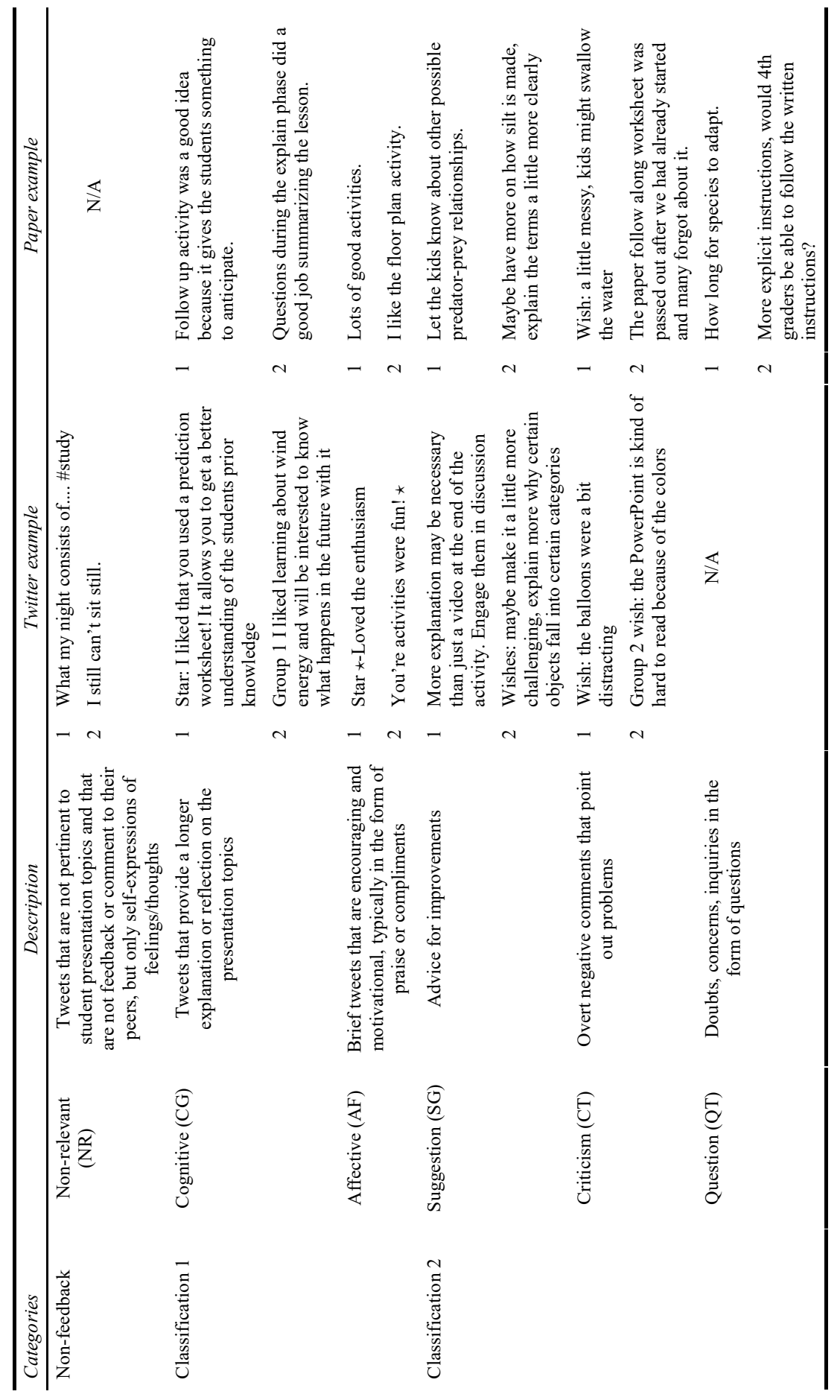




\section{Results}

\subsection{Amount of feedback}

Nearly an equal number of students took part in the Twitter- and paper-based peer teaching sessions. Only one student opted out of the Twitter experiment. Students tweeted feedback more frequently than writing their feedback on paper. Quantitative measures of feedback posts were almost equal in number when we counted the average word and character length between the two environments (see Table 2). Interestingly on average, students posted fewer words and characters than what they did in the Twitter environment. Practically speaking, Twitter's 140-character limit did not impose a constraint on the length of text based on this comparative data.

Table 2 Quantity and average length of feedback

\begin{tabular}{lcccc}
\hline Mode & \# of students & Total \# of posts & $\begin{array}{c}\text { Average \# of } \\
\text { character per post }\end{array}$ & $\begin{array}{c}\text { Average \# of word } \\
\text { per post }\end{array}$ \\
\hline Twitter & 29 & 425 & 56.5 & 9 \\
Paper & 30 & 326 & 53.6 & 8.9 \\
\hline
\end{tabular}

\subsection{Relevancy of feedback}

With regard to relevancy of feedback, 94.8\% (403 out of 425) was relevant in the Twitter-based session. The proportion of relevant feedback in Twitter-based sessions was much higher than data reported in previous studies [compared to Luo $(2015,2016)]$. The vast majority of students were able to focus on their task to provide relevant feedback in the Twitter platform. Not surprisingly, all the 326 paper-based feedback was also of a relevant nature, though it was noticeable that some of the students doodled slightly on the handwritten feedback.

\subsection{Type of feedback}

Our data shows that $92.3 \%$ of the Twitter-based feedback was CG feedback with the remainder being AF in nature. The paper-based feedback consisted of $91.1 \% \mathrm{CG}$ feedback and $8.9 \%$ AF (see Table 3). Among all the CG feedback in the paper-based session, $41.4 \%$ (123 out of 297) was constructive feedback, while in the Twitter-based session, 47.8\% (178 out of 372) was constructive feedback, as shown in Table 4.

Table 3 Classification 1-CG and AF feedback

\begin{tabular}{lcc}
\hline & CG-cognitive & AF-affective \\
\hline Twitter & $92.3 \%(372 / 403)$ & $7.7 \%(31 / 403)$ \\
Paper & $91.1 \%(297 / 326)$ & $8.9 \%(29 / 326)$ \\
\hline
\end{tabular}

In the process of parsing constructive feedback, we found that the Twitter-based feedback was composed of $93.8 \%$ (167 out of 178) suggestions, $6.2 \%$ (11 out of 178) criticisms, but no questions. Contrastingly, during paper-based sessions, $78.9 \%$ (97 out of 123 ) were suggestions, $17.9 \%$ (22 out of 123) were criticisms, and 3.2\% (4 out of 123 ) were questions. It seemed that students were prone to evoke criticism and raise questions when 
using paper to provide feedback, while more suggestive feedback was given in the Twitter environments.

Table 4 Classification 2-constructive feedback

\begin{tabular}{lcccc}
\hline & $\begin{array}{c}\text { Proportion of constructive } \\
\text { feedback among all } \\
\text { cognitive feedback }\end{array}$ & SG-suggestion & CT-criticism & QT-question \\
\cline { 3 - 5 } & $47.8 \%(178 / 372)$ & $93.8 \%(167 / 178)$ & $6.2 \%(11 / 178)$ & $0 \%(0 / 178)$ \\
Twitter & $41.4 \%(123 / 297)$ & $78.9 \%(97 / 123)$ & $17.9 \%(22 / 123)$ & $3.2 \%(4 / 123)$ \\
Paper & & & & \\
\hline
\end{tabular}

\subsection{Student perceptions}

Eight out of 30 students voluntarily participated in completing the end-of-course survey. Despite that these eight students were insufficient to represent the whole group, we believe this data is valuable in enabling us to identify some common themes and issues occurring in the Twitter activity. According to our data, there existed a large variability in students' perceptions toward Twitter as a tool to support the delivery and reception of peer feedback. Overall, students were able to post and provide feedback on the Twitter platform, but, at times some were having difficulties retrieving and locating their feedback afterwards. Two of the eight survey students were not able to receive Twitter-based feedback from their peers. Most revealed positive attitudes about the peer teaching experiences. Students also reported some challenges, including accessibility and distractions from the learning activity.

When reflecting on their class experience with Twitter, these eight students agreed that the peer teaching activity supported by Twitter allowed them to critique and evaluate their classmates' teaching. One student stated, "it showed me what I could improve on". They remained neutral or disagreed slightly with regard to observing and learning from received feedback, constructing their own learning and interaction between themselves and the course instructor (see Table 5). Many believed that providing Twitter-based feedback was fun and enjoyable, and some commented that the activity made them concentrate and engage (see Table 6). As one student said, "I enjoyed the uniqueness of the experience". Another student stated that "it (Twitter-supported activity) made me focus and concentrate on the lesson so I could give good feedback."

Table 5 Benefits of Twitter-supported peer teaching activity

\begin{tabular}{lc}
\hline The peer teaching activity supported by Twitter allowed me to & Mean (SD) $(N=8)$ \\
\hline Critique and evaluate my classmates' teaching & $4.63(0.52)$ \\
Learn from my classmates' feedback & $3.13(1.36)$ \\
Interact with the course instructor & $3.50(1.51)$ \\
Observe my peers' learning & $3.38(1.19)$ \\
Construct my own learning & $3.38(1.19)$ \\
Improve my own teaching & $3.50(1.41)$ \\
\hline
\end{tabular}

Notes: 1 = strongly disagree; 2 = disagree; 3 = slightly disagree; 4 = slightly agree; $5=$ agree; $6=$ strongly agree. 
Table 6 Advantages of Twitter-supported peer teaching activity

\begin{tabular}{lc}
\hline The peer teaching activity supported by Twitter & Mean $(S D)(N=8)$ \\
\hline Made me concentrate on task & $3.50(2.00)$ \\
Engaged me in the process of providing and receiving feedback & $3.75(2.79)$ \\
Made the task fun and enjoyable & $4.13(2.13)$ \\
\hline
\end{tabular}

Notes: 1 = strongly disagree; 2 = disagree; 3 = slightly disagree; 4 = slightly agree; $5=$ agree; $6=$ strongly agree.

In terms of the affordances and challenges of Twitter-based feedback, students valued most the timeliness of feedback that Twitter affords. Some agreed that the Twitter feedback was relevant, succinct, useful, and clear (see Table 7). One major obstacle was that students pervasively had difficulty locating the Twitter feedback from their classmates, as revealed in the open-ended question. One student said, "...I am unable to go back and review comments made regarding my instruction." Another student commented, "It was hard to find feedback that other classmates had given me." Another concern was the lack of anonymity. As a student mentioned, "The only thing not so good about it is everyone can see what feedback you are getting." Twitter's 140-character limit also seemed to have posed a challenge for some students. A student pointed out that "the limitation on the number of characters sometimes prevents the user from articulating his or her ideas fully." While students considered Twitter feedback to be valuable, they "wish[ed] the criticisms were not limited by character restraints." Students also attributed the potential difficulties in providing feedback to the availability of mobile devices as opposed to using a web browser version of Twitter - "I constantly utilize technology, but giving feedback via this method often seemed cumbersome. Perhaps the experience was more negative due to using the mobile version of Twitter." Nonetheless, they also recognised that unfamiliarity with legitimate learning in the Twitter environment was another resisting factor because they could be easily sidetracked by the other unintended uses of mobile devices when they are readily available at hand.

Table 7 Quality of Twitter-based feedback

\begin{tabular}{lc}
\hline $\begin{array}{l}\text { Please rate the following statements regarding the feedback you received } \\
\text { from your peers on Twitter }\end{array}$ & Mean $(S D)(N=8)$ \\
\hline I received timely feedback & $4.00(1.85)$ \\
I received relevant feedback & $3.75(1.67)$ \\
The feedback is succinct & $3.88(1.73)$ \\
The feedback is useful & $3.63(1.60)$ \\
The feedback is clear & $3.63(1.60)$ \\
\hline
\end{tabular}

When comparing students' paper-based with Twitter-based peer instruction experience, the eight students reported similar levels of interest in providing feedback using paper and Twitter. In agreement with our data in the open-ended questions, students felt more apt and facile to be involved and focused in the paper feedback session. Contrastingly, students had much higher level of enjoyment in the Twitter session (see Table 8). They expressed that they "had more fun" in the Twitter-based activities. 
Table 8 Comparison of peer instruction experience in paper and Twitter sessions

\begin{tabular}{lc}
\hline $\begin{array}{l}\text { Compare your paper-based peer feedback experience to Twitter-based } \\
\text { peer feedback experience. Rate the following items for each type of }\end{array}$ & $\begin{array}{c}\text { Mean (SD) } \\
\text { feedback format on a scale of 1 to 100. }\end{array}$ \\
\hline My degree of interest in providing feedback using PAPER & $54.13(30.91)$ \\
My degree of interest in providing feedback using Twitter & $52.13(27.28)$ \\
My degree of involvement in providing feedback using PAPER & $71.75(27.57)$ \\
My degree of involvement in providing feedback using Twitter & $58.88(16.79)$ \\
My degree of focus when providing feedback using PAPER & $75.00(27.71)$ \\
My degree of focus when providing feedback using Twitter & $59.50(12.47)$ \\
My degree of enjoyment when providing feedback using PAPER & $37.63(21.36)$ \\
My degree of enjoyment when providing feedback using Twitter & $61.38(28.58)$ \\
\hline
\end{tabular}

\subsection{Instructor feedback and perceptions}

All the instructor's Twitter feedback $(\mathrm{N}=35)$ was $\mathrm{CG}$ in nature. Among the CG feedback, 48.6\% (17 out of 35) was constructive feedback, which consisted of 70.6\% (12 out of 17) suggestions, 29.4\% (5 out of 17) questions, and no criticism (see examples in Table 9).

Table 9 Instructor constructive feedback

\begin{tabular}{|c|c|c|c|}
\hline Codes & Percentage & & Examples of Tweets \\
\hline \multirow[t]{2}{*}{$\mathrm{CG}$} & $48.6 \%(17 / 35)$ & 1 & $\begin{array}{l}\text { \#pt3400. great job distinguishing bet soil \&amp; dirt using } \\
\text { scientific definition \&amp; setting the use of scientific terms as } \\
\text { an expectation. }\end{array}$ \\
\hline & & 2 & $\begin{array}{l}\text { \#pt3400. great use of hints to scaffold student work during the } \\
\text { explore phase. }\end{array}$ \\
\hline \multirow[t]{2}{*}{ SG } & $70.6 \%(12 / 17)$ & 1 & $\begin{array}{l}\text { \#pt3400. transitions needed so that } 5 \text { th graders don't get lost or } \\
\text { confused. They may also need more structure for materials } \\
\text { management. }\end{array}$ \\
\hline & & 2 & $\begin{array}{l}\text { \#pt3400. you use many appropriate high level convergent } \\
\text { questions. I would like to see you also use some more } \\
\text { divergent questions. }\end{array}$ \\
\hline $\mathrm{CT}$ & $0 \%(0 / 17)$ & & $\mathrm{N} / \mathrm{A}$ \\
\hline \multirow[t]{2}{*}{ QT } & $29.4 \%(5 / 17)$ & 1 & $\begin{array}{l}\text { \#pt3400. great summary activity with Simon says. How can } \\
\text { you engage students in summarizing too ( they come up with } \\
\text { some of statements) }\end{array}$ \\
\hline & & 2 & $\begin{array}{l}\text { \#pt3400. how can u make definitions shared in ppt more grade } \\
\text { appropriate and get students to make sense of them }\end{array}$ \\
\hline
\end{tabular}

The course instructor described her experience with Twitter-based feedback during the peer teaching exercise as mostly positive. This study constituted the instructor's first experience with Twitter. The instructor shared that, prior to the study, she was concerned that the character limit within the Twitter-based environment was going to constrain the level of feedback she could provide to her students. After the experience, the instructor stated "I was most surprised to realize that the character limit forced me to be succinct 
and to the point. It made my feedback clearer." The instructor also highlighted the public nature of the feedback. She indicated that this feature of Twitter forced her to think about how to positively phrase her feedback and to avoid criticism so as not to embarrass the students.

In terms of student use, the instructor shared that she was impressed with the level of student engagement in Twitter. Prior to this course, preservice teachers tended to opt out of providing feedback unless the feedback was required. When prompted, feedback tended to focus on providing praise (e.g., 'great job') or describing the features of the lesson that they most liked. She stated, "In this course, feedback provided by the students was different, even when we used paper and pencil...I think describing the types of feedback that could be provided gave students concrete ideas about what and how to provide feedback." The instructor shared that it was a little 'different' for her to use Twitter in her classroom. She stated, "Trusting that the students are using their phone for instructional purposes was hard for me." Finally, the instructor commented that the use of Twitter-based feedback was environmentally friendly: "We used less paper than we have ever done in this course!"

\section{Discussions}

The comparative analysis between Twitter-based versus paper-based feedback, coupled with the qualitative analysis of student and instructor perceptions, offered some insights as to what might be the ways Twitter could outperform paper as a medium for providing student feedback. Despite the scepticism that some students exhibited in the qualitative data, we believe that the level of student learning represented in quantity and quality of feedback posts during the Twitter-supported peer instruction sessions is at least on par with paper-based feedback, if not better. Twitter outperformed paper with respect to frequency of feedback, and past research showed that frequency can lead to improved performance (Goodman et al., 2011). In contrast to prior studies where roughly 20 to $40 \%$ of tweets were off-task (Luo, 2015, 2016), a minimal number of only $5.2 \%$ (22 tweets) irrelevant tweets shows that alongside instructor modelling to provide explicit scaffolding, students were fully engaged in the peer learning activities without being distracted with other activities. Through a close examination of 22 tweets that were not considered feedback, we found that they were primarily tweets posted at the forefront of the activity when students attempted to test the Twitter platform by repeatedly posting the hashtag for the course. In other words, according to our data, students were very rarely distracted or posted non-class related content during these Twitter-based activities. This result reaffirmed that with proper guidance, the quality of student learning does not have to be compromised simply because students were given opportunities to reorient their learning in an open, and sometimes 'messy' social media platform. Instructor's guidance is undeniably instrumental to the success of such social media-supported activities.

Despite that we cheer for keeping our students on task, we realised that in Twitter-supported environments students would need an enormous amount of additional instructional support to build their capacities in providing constructive feedback that is in-depth, thought-provoking, and worth contemplating. After all, providing constructive feedback is never an easy task regardless of the medium. It requires the ability to correctly diagnose the gap between desired and current understanding and performance, 
delivering instructional support and strategies that can lead to successful and improved learning (Alves de Lima, 2008; Hattie and Timperley, 2007; Ovando, 1994). The guidance and structure that we provided in this case may have raised students' attention and interest in providing constructive feedback. We speculated that instructor modelling of the act of tweeting out feedback had a positive impact on student behaviours. However, we believe that students as novice learners in the subject-matter area require far more content knowledge and support to be able to offer constructive feedback, even in a traditional paper-based environment. Processing information and writing in a novel platform, Twitter, might have added an additional layer of difficulty in providing peer feedback, a process that is challenging in and of itself and does not come naturally. Prior research also indicated that user familiarity with Twitter plays a role in their perceived learning (Luo and Franklin, 2015).

What is equally striking is the overwhelming amount of suggestive feedback found in the tweets as compared to criticisms. Research suggests that distinctions between the type of feedback and how it is given define and determine its effectiveness (Hattie and Timperley, 2007). Albeit that the instructor mandated "two stars and two wishes" which in some ways stipulate the type of feedback, students are more inclined to provide direct criticism on paper than in the Twitter environment. We speculate that this higher amount of non-criticism type of suggestive feedback may be attributable to a lack of anonymity, as students mostly disclosed their real names and even used the @ symbol to direct the message to another student on Twitter. The technology-enforced transparency in Twitter demanded students to be more cautious of their tone of language used in writing feedback. Though the difference between a criticism and a suggestion may purely be a matter of semantics, on Twitter students become more likely to use a suggestive style of speech that can help peer learners divert the discourse from direct criticism to potential answers and solutions identifying weaknesses and problems in a positive way. Simply put, making the comment transparent allows students to seamlessly identify who the supplier of feedback is, therefore helping to foster an open, nurturing, and supportive peer learning environment. Such a positive feedback mechanism can, in turn, make a tremendous difference to the student who is on the receiving end, as it preserves the learners' self-esteem and poses a reduced amount of threat to the learners' personal self-image (Kinch, 1963, 1968; Nussbaum and Dweck, 2008).

\section{Pedagogical suggestions}

Finally, based on the results of this study, we propose the following pedagogical suggestions for practice. First, we believe it is critically important to set some ground rules when certain social media tools such as Twitter are introduced to the classroom. Instructors and students shall not have the unrealistic expectation that Twitter can be a magic wand solving all instructional problems occurring in the classroom. As Twitter is not superficially designed to be an educational technology utilised in the classroom, the system in and of itself possesses inevitable imperfections when it comes to facilitating classroom instruction. Nor should Twitter be a gimmicky tool that intervenes into classroom instruction; momentarily appearing and fleeting, having no connection to the goals and objectives of the instruction. Expectancy management is crucial in successfully leveraging student learning so that students will not be appalled or shied away by any potential technical glitches or technological discomfort. 
Second, instead of being the single, stand-alone medium for supporting peer instruction, Twitter seems to be more apt for a 'facilitating' or complementary pedagogical tool that can be integrated along with other forms of instructional activities and strategies in a dynamic learning ecosystem. In this study, aside from the front-end peer teaching demonstration that took place in concurrence with Twitter-mediated feedback, students were also instructed to write a reflection essay as part of the activity in order to validate whether or not the feedback was utilised. Additionally, the instructor posted his/her detailed feedback for students both on paper and via Twitter which at the same time provided oversight to the activity. All of these were critical components to the entirety of the peer teaching activity. It was a connected, well-rounded, and organic instructional activity in which Twitter played an important role in the learning ecosystem (Brown, 2000; Siemens, 2014), but it did not stop at the Twitter phase. The reflection paper and instructor feedback built on what Twitter had facilitated and progressively enhanced. How to recalibrate the design of Twitter-supported learning environments and place it as a subset constituting an overall learning ecosystem is worth considering.

Lastly, we cannot stress enough the pivotal role of instructional guidance in any Twitter-afforded instructional interventions. The importance of instructional guidance has repeatedly been underscored in research on microblogging in education (Dunlap and Lowenthal, 2009; Gao et al., 2012; Holotescu and Grosseck, 2009; Luo, 2015). In this study, having instructor model the practice of tweeting on the side was a particular strategy we used that could have plentiful applications in other contexts and situations. Using the Twitter-based feedback taxonomy to demonstrate a spectrum of varied levels of feedback is another strategy we found valuable in this study. Employing these instructional strategies and techniques can help combat technical difficulties and aid students in developing a positive outlook favouring the use of technology in face of adversity.

\section{Conclusions, limitations, and recommendations for future research}

The use of Web 2.0 technologies has been increasingly seen as a tool to support peer instruction over the past decade (Lin et al., 2001; Tseng and Tsai, 2007). In our study, the integration of Twitter as a Web 2.0 tool enhanced immediacy and flexibility in exchanging feedback. It allowed instructors to continuously monitor students' progress; meanwhile alleviating cost and circumventing logistical obstacles through the administration of paper-based feedback. Most students had positive experiences in the peer instruction activities, reporting a fun and enjoyable atmosphere while maintaining concentration and focus. Compared to paper-based feedback, Twitter feedback was much more simplified; though some students did have difficulties with accessing their feedback. This is quite possibly due to unfamiliarity with the Twitter platform. We also found that the lack of anonymity in Twitter perhaps influenced students to provide more feedback of a suggestive nature, rather than direct criticisms. Future research can focus on these areas to investigate whether or not such factors make a difference in Twitter-based peer feedback.

This study presents an initial effort at describing how Twitter can support peer instruction as opposed to paper and pencil in teacher education classrooms. We recognise that due to the small sample size and the constrained classroom learning environment, 
this study may not be generalisable in other circumstances. A study on a larger scale with more representative data from surveys and/or interviews is necessary for future studies to further investigate the effects of using Twitter to provide real time peer feedback. This study was conducted in a naturalistic educational setting, in which the confounding variables make it difficult to compare the effects of Twitter versus paper to provide feedback scientifically. More rigorous methods such as quasi-experimental or experimental research designed to better control extraneous variables are recommended for comparison on a more intimate level.

\section{References}

Alves de Lima, A. (2008) 'Constructive feedback: a strategy to enhance learning', Medicina (B Aires), Vol. 68, No. 1, pp.88-92.

Borau, K., Ullrich, C., Feng, J. and Shen, R. (2009) 'Microblogging for language learning: using Twitter to train communicative and cultural competence', Paper presented at the Advances in Web Based Learning-ICWL 2009.

Brookhart, S.M. (2008) How To Give Effective Feedback To Your Students, ASCD, Alexandria, VA.

Brown, J.S. (2000) 'Growing up digital: how the web changes work, education, and the ways people learn', Change: The Magazine of Higher Learning, Vol. 32, No. 2, pp.11-20.

Chan, C. and Cmor, D. (2009) 'Blogging toward information literacy: engaging students and facilitating peer learning', Reference Services Review, Vol. 37, No. 4, pp.395-407.

Costa, C., Beham, G., Reinhardt, W. and Sillaots, M. (2008) 'Microblogging in technology enhanced learning: a use-case inspection of PPE summer school 2008', Paper presented the Workshop on Social Information Retrieval for Technology Enhanced Learning.

Crouch, C.H. and Mazur, E. (2001) 'Peer instruction: ten years of experience and results', American Journal of Physics, Vol. 69, No. 9, pp.970-977.

Crouch, C.H., Watkins, J., Fagen, A.P. and Mazur, E. (2007) 'Peer instruction: engaging students one-on-one, all at once', Research-Based Reform of University Physics, Vol. 1, No. 1, pp.40-95.

Du Toit, E. (2012) 'Constructive feedback as a learning tool to enhance students' self-regulation and performance in higher education', Perspectives in Education, Vol. 30, No. 2, pp.32-40.

Duffy, K. (2013) 'Providing constructive feedback to students during mentoring', Nursing Standard, Vol. 27, No. 31, pp.50-60.

Dunlap, J.C. and Lowenthal, P.R. (2009) 'Tweeting the night away: using Twitter to enhance social presence', Journal of Information Systems Education, Vol. 20, No. 2, pp.129-155.

Fagen, A.P., Crouch, C.H. and Mazur, E. (2002) 'Peer instruction: results from a range of classrooms', The Physics Teacher, Vol. 40, No. 4, pp.206-209.

Farivar, S. and Webb, N.M. (1993) 'Helping - an essential skill for learning to solve problems in cooperative groups', Cooperative Learning, Vol. 13, No. 1, pp.20-23.

Gagné, R.M., Wager, W.W. and Briggs, L.J. (1992) Principles of Instructional Design, 4th ed., Holt, Rinehart and Winston, New York.

Gao, F., Luo, T. and Zhang, K. (2012) 'Tweeting for learning: a critical analysis of research on microblogging in education published in 2008-2011', British Journal of Educational Technology, Vol. 43, No. 5, pp.783-801.

Goldschmid, B. and Goldschmid, M.L. (1976) 'Peer teaching in higher education: a review', Higher Education, Vol. 5, No. 1, pp.9-33.

Goodman, J.S., Wood, R.E. and Chen, Z. (2011) 'Feedback specificity, information processing, and transfer of training', Organizational Behavior and Human Decision Processes, Vol. 115, No. 2, pp.253-267. 
Gropper, G.L. (1983) 'A metatheory of instruction: a framework for analyzing and evaluating instructional theories and models', in Reigeluth, C.M. (Ed.): Instructional-Design Theories and Models: An Overview of Their Current Status, pp.37-53, Lawrence Erlbaum Associates, New Jersey.

Hall, H. and Davison, B. (2007) 'Social software as support in hybrid learning environments: the value of the blog as a tool for reflective learning and peer support', Library and Information Science Research, Vol. 29, No. 2, pp.163-187.

Hattie, J. and Timperley, H. (2007) 'The power of feedback', Review of Educational Research, Vol. 77, No. 1, pp.81-112.

Hendry, G.D., Bromberger, N. and Armstrong, S. (2011) 'Constructive guidance and feedback for learning: the usefulness of exemplars, marking sheets and different types of feedback in a first year law subject', Assessment and Evaluation in Higher Education, Vol. 36, No. 1, pp.1-11.

Holotescu, C. and Grosseck, G. (2009) 'Using microblogging in education: case study: Cirip.ro', Paper presented at the 6th Conference on e-Learning Applications [online] http://www.scribd.com/doc/8551345/Using-microblogging-in-education-Case-Study-Ciripro (accessed 2 October 2016).

Kinch, J.W. (1963) 'A formalized theory of the self-image', American Journal of Sociology, Vol. 68, No. 1, pp.481-486.

Kinch, J.W. (1968) 'Experiments on factors related to self-concept change', Journal of Social Psychology, Vol. 74, No. 2, pp.251-258.

Lin, S.J., Liu, E.F. and Yuan, S.M. (2001) 'Web-based peer assessment: feedback for students with various thinking-styles', Journal of Computer Assisted Learning, Vol. 17, No. 4, pp.420-432.

Luo, T. (2015) 'Instructional guidance in microblogging-supported learning: insights from a multiple case study', Journal of Computing in Higher Education, Vol. 27, No. 3, pp.173-194.

Luo, T. (2016) 'Enabling microblogging-based peer feedback in face-to-face classrooms', Innovations in Education and Teaching International, Vol. 53, No. 2, pp.156-166.

Luo, T. and Franklin, T. (2015) 'Tweeting and blogging: moving towards Education 2.0', International Journal on E-Learning, Vol. 14, No. 2, pp.235-258.

Luo, T. and Gao, F. (2012) 'Enhancing classroom learning experience by providing structures to microblogging-based activities', Journal of Information Technology Education: Innovations in Practice, Vol. 11, No. 1, pp.199-211.

McLoughlin, C. and Lee, M.J. (2007) 'Social software and participatory learning: pedagogical choices with technology affordances in the Web 2.0 era', Proceedings Ascilite, ICT: Providing Choices for Learners and Learning, December, pp.664-675, Singapore, Malaysia.

Merrill, M.D. (1983) 'Component display theory', in Reigeluth, C.M. (Ed.): Instructional Design Theories and Models, pp.279-334, Lawrence Erlbaum, Hillsdale, NJ.

Metcalf, K.K. (1993) 'Critical factors in on-campus clinical experience', Teaching Education, Vol. 5, No. 2, pp.164-174.

Mills, R.F. (1991) 'Micro-peer teaching: organization and benefits', Education, Vol. 111, No. 4, pp.559-562.

Nelson, M.M. and Schunn, C.D. (2009) 'The nature of feedback: how different types of peer feedback affect writing performance', Instructional Science, Vol. 37, No. 4, pp.375-401.

Nottingham, S. and Henning, J. (2014) 'Feedback in clinical education, part I: characteristics of feedback provided by approved clinical instructors', Journal of Athletic Training, Vol. 49, No. 1, pp.49-57.

Nussbaum, A.D. and Dweck, C.S. (2008) 'Defensiveness vs. remediation: self-theories and modes of self-esteem maintenance', Personality and Social Psychology Bulletin, Vol. 34, No. 5, pp.599-612.

Ovando, M.N. (1994) 'Constructive feedback: a key to successful teaching and learning', International Journal of Educational Management, Vol. 8, No. 6, pp.19-22. 
Puntambekar, S. and Hubscher, R. (2005) 'Tools for scaffolding students in a complex learning environment: what have we gained and what have we missed?', Educational Psychologist, Vol. 40, No. 1, pp.1-12.

Rosenberg, J.L., Lorenzo, M. and Mazur, E. (2006) 'Peer instruction: making science engaging', in Mintzes, J.J. and Leonard, (Eds.): Handbook of College Science Teaching, pp.77-85, NSTA Press, Arlington, VA.

Rourke, L. and Anderson, T. (2002) 'Using peer teams to lead online discussions', Journal of Interactive Media in Education, No. 1 [online] http://jime.open.ac.uk/articles/10.5334/2002-1/ (accessed 2 October 2016).

Siemens, G. (2014) 'Connectivism: a learning theory for the digital age' [online] http://er.dut.ac.za/bitstream/handle/123456789/69/Siemens 2005 Connectivism A learning t heory for the digital age.pdf?sequence=1\&isAllowed=y (accessed 2 October 2016).

Tseng, S. and Tsai, C. (2007) 'On-line peer assessment and the role of the peer feedback: a study of high school computer course', Computers and Education, Vol. 49, No. 4, pp.1161-1174.

Vygotsky, L. (1978) Mind in Society: The Development of Higher Psychological Processes, Harvard University Press, Cambridge, MA.

Warren, S.J. (2016) 'The Twitter academic: supporting learning communications in 140 characters or less', International Journal of Social Media and Interactive Learning Environments, Vol. 4, No. 1, pp.1-22.

Whitman, N.A. (1988) Peer Teaching: To Teach is to Learn Twice, Jossey-Bass, San Francisco, CA.

Yin, R.K. (2008) Case Study Research: Design and Methods, Sage, Thousand Oaks, CA. 